\title{
Preliminary Results for Detection Evaluation in Failure Modes and Eftect Analysis Study: 600 kW Wind Turbine Case Study
}

\author{
A. G. Papatsounis*, P. N Botsaris and P. P. Pistofidis \\ Democritus University of Thrace, School of Engineering, Dep. of Production Engineering and Management, Lab. of mechanical De- \\ sign, Faculty of Materials, Processes and Mechanics, www.medilab.pme.gr
}

Received 26 October 2020; Accepted 16 December 2020

\begin{abstract}
In recent years, the need for renewable and sustainable energy is greater than ever before. Wind turbines in a variety of sizes, appear in every available area and participate in our effort to reverse the energy crisis. However, these complex electromechanical systems are defined by low availability and substantial downtime periods. The Levelised Cost of Energy (LCOE) and the Internal Rate of Return (IRR) only recently started to be encouraging for investors. One of the key factors to be taken into consideration is that the reliability of these systems is often compromised due to their ever-growing nominal power and harsh operating conditions, fault appearances increase exponentially from $1 \mathrm{MW}$ wind turbine to $10 \mathrm{MW}$ or more. To assess the reliability of a case-study wind turbine of $600 \mathrm{~kW}$, a Failure Modes and Effects Analysis (FMEA) was used to identify the potential causes of downtimes. In this paper, a novel way to approach detection evaluation in the FMEA study is proposed. The results indicate a reliable way to identify the most critical components of a complex system.
\end{abstract}

Keywords: wind turbines, FMEA, failure detection, critical subsystems, RPN

\section{Introduction}

Harvesting the power of wind has been at the forefront of engineering for more than 20 years. Onshore and offshore wind turbines (WT) of ever-growing sizes and shapes (Vertical Axis Wind Turbines-VAWT, Horizontal Axis Vertical Wind Turbines-HAWT, etc.) have been installed in the European fields and mountains every year, in an attempt to increase the penetration of Renewable Energy Sources (RES). The Global Wind Energy Council (GWEC), at its latest report, announced reforms that will assist and speed up the energy transition worldwide. The cumulative installations reached $591 \mathrm{GW}$ and are anticipated to increase by $50 \mathrm{GW}$ each year until 2023 [12]. Due to this exponential growth in installed capacity (see Fig. 1), optimizing the operation of WT will be the key factor of the energy transition. WT, as shown in Fig. 2, are complex electromechanical systems that exploit the kinetic energy of the wind and transform it into electrical energy [3].

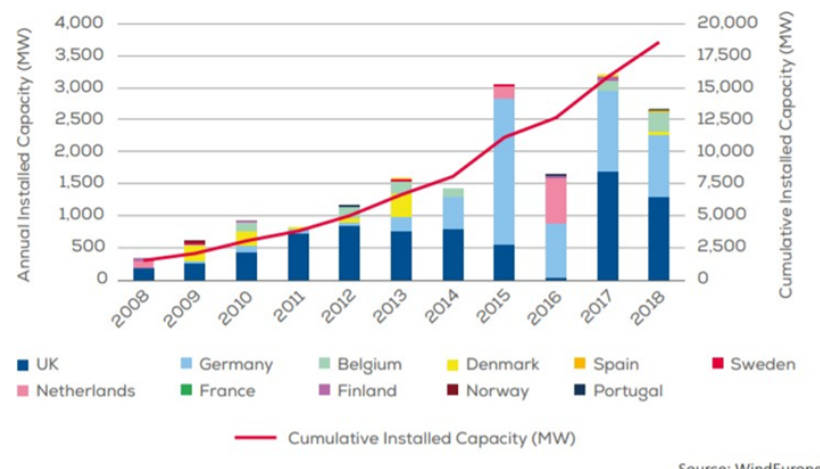

Fig. 1. European cumulative installed capacity from wind turbines, in MW, 2008-2018

*E-mail address: adpapat@gmail.com

ISSN: $1791-2377$ @ 2020 School of Science, IHU. All rights reserved. doi:10.25103/jestr.136.13
FMEA is a bottom-up analysis, which evaluates the riskiness of a failure occurring at the bottom level of the structure of a system, at the component level [8]. It is commonly used on WTs in many different variations and approaches. A. Benouk et al performed a Risk-Based FMECA (a combination of FMEA and Criticality Analysis) using SCADA and Lidar systems, to propose maintenance actions, on a $2.3 \mathrm{MW}$ onshore WT, and achieved positive changes in turbine performance [9]. Anmei Zhou et al, approached FMECA's results via ontology to more accurately assess the outcome of the analysis and provide to the maintenance personnel, structured data [10]. Guerrero A. Crespo et al. proposed a novel approach using asset maintenance based on ISO: 14224 and the OREDA database to enrich an FMECA study and present to the maintenance personnel reliability information about the WT [11].

The aforementioned approaches to FMEA took into consideration the generic faults of its risk classification tool, Risk Priority Number (RPN). The RPN consists of three parameters, each expressing an aspect of the failure mode. These parameters are the Severity of the failure (S), the probability of occurring-Occurrence $(\mathrm{O})$ and its possibility of Detection (D). In 1993, Gilchrist et al. characterized RPN as inconsistent and thus introduced cost in the model [12].

N. R. Sankar proposed a new approach to FMEA to better classify the parameters, which contribute to the assessment of the risk at RPN [13]. Kuei-Hu Chang et al. were the first to introduce a new method, exponential RPN (ERPN), of combining the parameters which constitute the RPN [14]. Their work was continued and enhanced by Hadi A. Khorshidi et al. who approached the calculation of the RPN number using the Universal General Function (UGF) [15]. Their approach was named URPN (Universal RPN) and the parameters of the RPN were separated and special weight had been given to the most important (Severity). 
However, the rich bibliography surrounding FMEA studies, little emphasis has been given at the classification and the distinction of the parameters involved and the transition from qualitative to quantitative. John B. Bowles et al. introduced the fuzzy logic approach when tackling the prioritization of the failure modes and the enhancement of the distinction of the three parameters [16]. Another major issue is the definition of the way the three values are estimated. The Guidelines for the Naval Aviation Reliability-Centered Maintenance Process refers to the parameter of Severity as the measure of the impact the failure has on the functionality of the system [17]. Occurrence has been presented as the expression of the probability of the appearance of the failure during the lifetime of the system. Detection has been referred to as the quantification of the possibility the measurement method will detect the failure when it occurs [18]. As far as detection (D) is concerned, the quantitative equivalent of the quality remark of the detection method is subjected to the teams' expertise and ability to accurately evaluate it.

In this paper, a novel approach has been proposed, to mathematically approach D of the FMEA study. Two parameters are used for the evaluation, one refers to the Applicability of the Detection Method to each system's requirements and the second examines the Detectability of the Failure in each Failure Mode. To analyze the risk and determine the causes of the downtime periods of onshore WTs, in this paper, Failure Modes and Effect Analysis (FMEA) will be used on a $600 \mathrm{~kW}$ onshore WT which is part of a $10 \mathrm{WT}$-park.

The paper is divided as follows: the FMEA application on the case study of a $600 \mathrm{~kW}$ WT is presented in section 2 , in section 3 the proposed method is presented, results and further discussion of the findings are in section 4 and conclusions are in section 5 .

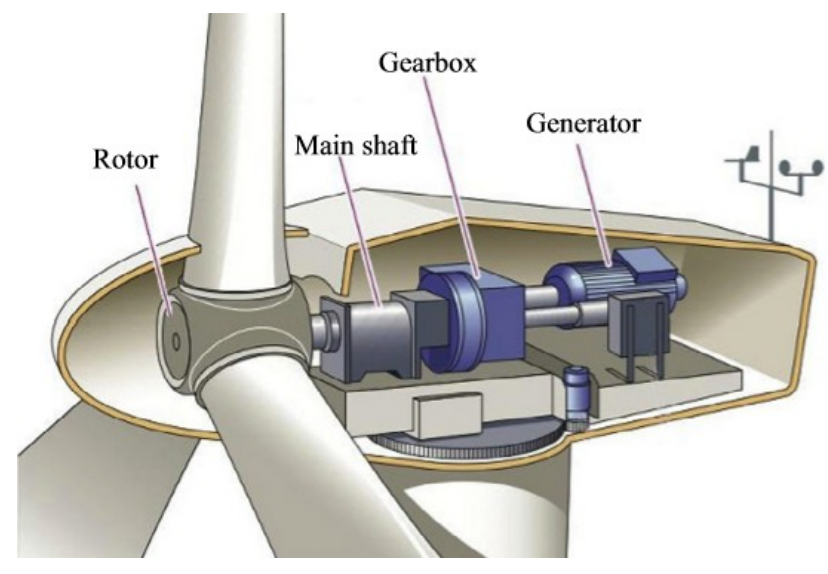

Fig. 2. Subsystems located at a typical WT nacelle [10]

\section{FMEA Study for The Case Study Of A $600 \mathrm{Kw} \mathrm{Wt}$}

\subsection{Defining the Objectives of FMEA study}

FMEA is a bottom-up approach of a system's numerous ways of failing. Bottom-up approach, because it focuses on identifying all the different failure modes at a component level, thus it is been referred to as component FMEA [18]. Component FMEA is subjected to the task 101 of the MIL-STD-1629A of the Department of Defense-USA (DoD) and is the main focus of the study presented in this paper [8]. The objectives when conducting an FMEA are:

- preparation for the worst-case-scenarios for every component of the system
- minimization of the downtimes of the system and the cost of repair due to preventive measures

- help the maintenance personnel identify and prioritize the most critical subsystems in a risk priority order (RPN) [18].

\subsection{Case study of $600 \mathrm{~kW} \mathrm{WT}$}

For this study, a system of a $600 \mathrm{~kW}$ WT has been chosen due to the access provided to some of the data of a 10-WT park in Southern East Greece, required to conduct the FMEA. The first step was the identification of the system's complexity and the definition of the failure's conveyance mechanism on the FTAs [19-20]. The selection of the most critical subsystems for the case study is presented in Tab. 1.

Table 1. Subsystems and Components of the $600 \mathrm{~kW}$ BONUS

Component
Failure of Internal Gear Slewing Bear-
ing System
Failure of Yaw Drive Shaft-Pinion
System
Failure of Yaw Gearbox System
Failure of Lubrication System
Failure of Yaw Motor System
Failure of Clamping Unit System
Failure of Gearbox Cover System
Failure of Gearbox Suspension System
Failure of Planet Wheels System
Failure of Sun Wheel System
Failure of Internal Gear Ring System
Failure of Two Stage Fixed Axis
Geared System
Failure of Lubrication Oil System
Electrical System
Failure of Power Feeder Cables Sys-
tem
Failure of Grounding System
Failure of Lightning Protection Sys-
tem
Failure of Electrical Protection System
Failure of Tubing-Hoses System
Failure of Capacitor Bank System
Failure of Thyristor System
Failure of Transformer System
Control System
Failure of Controller System
Failure of Uninterruptible Power Sup-
ply (UPS)
Failure of Signal Networking Hard-
ware System
Failure of Meteorological Station
Failure of Cable Twist Protection Sys-
tem
Failure of High-Speed Centrifugal Re-


Failure of Valves System

Failure of Rotating Union System

Failure of Centrifugal Release Unit

Table 2. Severity estimation: qualitative to quantitative

Linguistic Approach
Rank

The appearance of the

failure has no significant Unimportant Ef- 1

effect in the overall func- fect

tionality of the system

There is no obvious sing

of obstruction in the func- Minor Effect 2

tionality of the system

Because of the failure, the

system had to be stopped Medium Size Ef-3

and repair was necessary fect

The failure caused severe

damage to the system andSignificant Ef- 4

most probably are not re-fect

pairable

The failure occurs without

warning and when it does,Catastrophic Ef- 5

it has a catastrophic effectfect

on the EHS

After reviewing all the components' subsystems, the identification of the failure modes in each of them is to be determined. The failure of the component conveys upwards to a subsystem level and becomes the failure mode for the subsystem. The process of the failure conveyance has been repeated until the system level. The following step in Task 101, FMEA, is evaluating the $\mathrm{S}, \mathrm{O}, \mathrm{D}$ for the different failure modes. Ford Motor Company was the last to review the classification of the $\mathrm{S}, \mathrm{O}, \mathrm{D}$ and the proposed method of value assignment is given in Tab. 2 and Tab. 3. [21].

The corresponding table for Occurrence is not applicable in the present case study because of the lack of an accurate historical data for the WTs under consideration. Instead, O was approached as the mean time of failures for each component, for the 8.5 years of operation of the wind park. Severity is been approached in a 5-ranking scale

While conducting the case study, it should be noted that FMEA study is taking into consideration failures that happen individually, while the rest of the system operates properly. Each failure has no cause-effect relationship with the other.

\section{Proposed Method: Detection Evaluation By De- fining Two Parameters}

The evaluation of the D parameter of the FMEA study takes into account the ability of the measurement method (or the existence of a method that detects the failure). The difficulty lies, however, in the complexity of the system and the approachability of the component which has failed. In this study, a two-parameter approach is proposed which consists of the Applicability and the Detectability parameter. For calculating the first parameter, a thorough bibliographic review has been made to filter out the detection methods applied to the components under study. Building on the work of Konstantinidis et al., the $\mathrm{S}, \mathrm{O}$ values for the respective components are as presented in Tab. 4 [20].
Table 3. Detection estimation: qualitative to quantitative

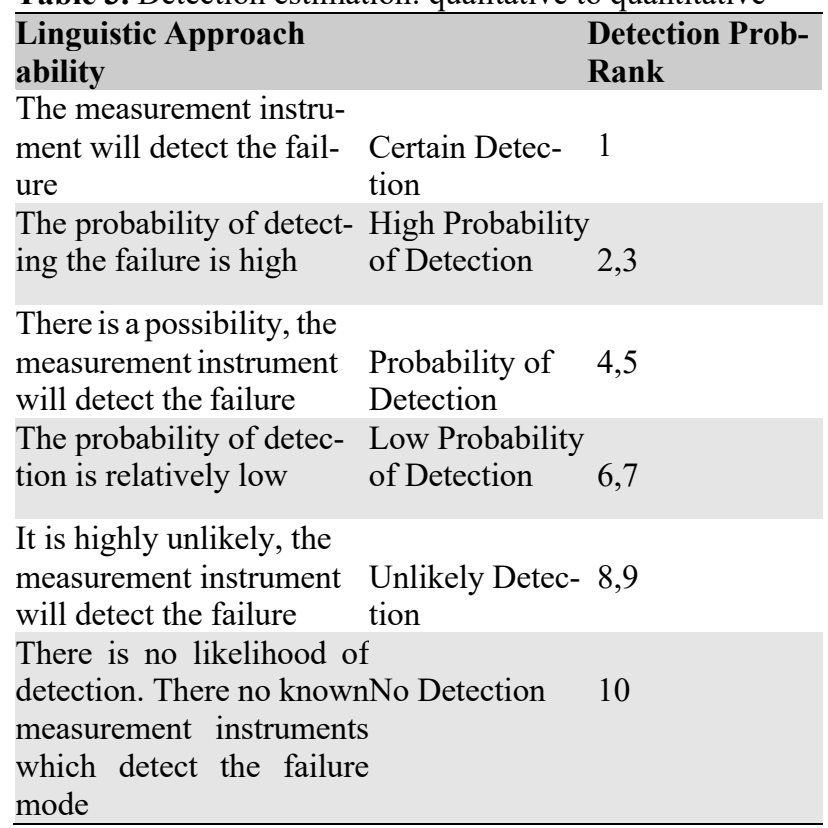

\subsection{1st Parameter: Applicability}

This parameter refers to the total number of components, of the system under consideration that the detection method detects. As shown in Fig. 3, each of the 9 methods, when applied, detects the failures of the components (marked with red asses). The goal of this parameter is to determine the adequacy of the method when applied to a system with a certain complexity. In the case study of the critical subsystems of the WT, Fig. 3 depicts the Applicability of the methods to the system. The calculation of the Applicability parameter $\left(A_{d}\right)$ is as shown in Eq. 1 .

$A_{d}=\frac{\sum_{c=1}^{c=N} X}{\max _{X} \sum_{c=1}^{c=N} X} \times \frac{100 \%}{20}$

Where $N$ is the total number of components, $c$ is the components whose failure is been detected with the method. The multiplication with 100 is used in order to extract the percentage of the applicability of the detection method. The division with 20 is used in order to cut down the result in a 5-scale system.

The equation returns a non-integer number which is then rounded-up to the nearest integer. The higher the value of $A_{d}$ the greater the applicability of the method in the respective system. Vibration analysis, for example, detects 22 from the total of 37 failures,

$\frac{22}{37} \times \frac{100 \%}{20}=2,97$

which rounds up in $A_{d}=3$. This value is calculated for all 9 detection method

Table 4. Severity and Occurrence values for the failures of the respective components [20]

\begin{tabular}{|c|c|c|}
\hline Subsystem & Component & \begin{tabular}{l|l}
$S$ & $O$
\end{tabular} \\
\hline \multirow{4}{*}{ 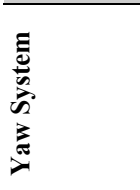 } & $\begin{array}{l}\text { Failure of Internal Gear Slewing Bearing } \\
\text { System }\end{array}$ & 25 \\
\hline & Failure of Yaw Drive Shaft-Pinion System & 31 \\
\hline & Failure of Yaw Gearbox System & 21 \\
\hline & Failure of Lubrication System & 31 \\
\hline
\end{tabular}




\begin{tabular}{|c|c|c|c|}
\hline & Failure of Yaw Motor System & 2 & 1 \\
\hline \multirow{8}{*}{ 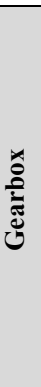 } & Failure of Clamping Unit System & 2 & 1 \\
\hline & Failure of Gearbox Cover System & 1 & 1 \\
\hline & Failure of Gearbox Suspension System & 2 & 1 \\
\hline & Failure of Planet Wheels System & 1 & 2 \\
\hline & Failure of Sun Wheel System & 5 & 2 \\
\hline & Failure of Internal Gear Ring System & 2 & 2 \\
\hline & $\begin{array}{l}\text { Failure of Two Stage Fixed Axis Geared } \\
\text { System }\end{array}$ & 4 & 2 \\
\hline & Failure of Lubrication Oil System & 5 & 7 \\
\hline \multirow{15}{*}{ 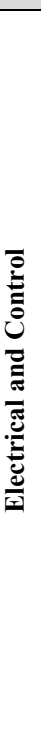 } & Electrical System & & \\
\hline & Failure of Power Feeder Cables System & 4 & 1 \\
\hline & Failure of Grounding System & 5 & 1 \\
\hline & Failure of Lightning Protection System & 5 & 1 \\
\hline & Failure of Electrical Protection System & 5 & 4 \\
\hline & Failure of Capacitor Bank System & 5 & 6 \\
\hline & Failure of Thyristor System & 2 & 1 \\
\hline & Failure of Transformer System & 0 & 1 \\
\hline & Control System & & \\
\hline & Failure of Controller System & 5 & 2 \\
\hline & $\begin{array}{l}\text { Failure of Uninterruptible Power Supply } \\
\text { (UPS) }\end{array}$ & 5 & 3 \\
\hline & $\begin{array}{l}\text { Failure of Signal Networking Hardware } \\
\text { System }\end{array}$ & 5 & 4 \\
\hline & Failure of Meteorological Station & 3 & 2 \\
\hline & Failure of Cable Twist Protection System & 5 & 2 \\
\hline & $\begin{array}{l}\text { Failure of High-Speed Centrifugal Release } \\
\text { Unit }\end{array}$ & 5 & 1 \\
\hline \multirow{9}{*}{ 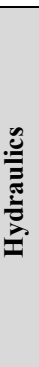 } & Failure of Electric Motor System & 1 & 1 \\
\hline & Failure of Pump System & 5 & 1 \\
\hline & Failure of Oil Tank System & 1 & 1 \\
\hline & Failure of Filters System & 1 & 2 \\
\hline & Failure of Tubing-Hoses System & 1 & 2 \\
\hline & Failure of (Pipe) Fittings System & 1 & 2 \\
\hline & Failure of Valves System & 5 & 1 \\
\hline & Failure of Rotating Union System & 5 & 2 \\
\hline & Failure of Centrifugal Release Unit & 5 & 1 \\
\hline
\end{tabular}

Table 5. Applicability of Detection Methods for the Components under study

INTERNAL

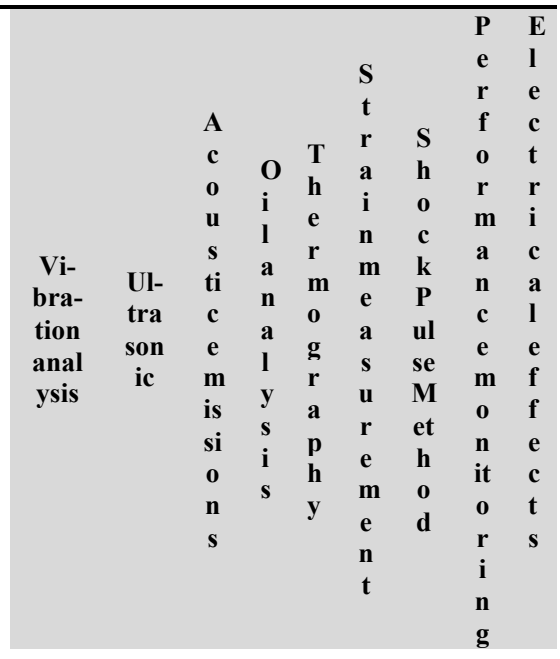

GEARED SLEW-

ING BEARING

SYSTEM

\begin{tabular}{|c|c|c|c|c|c|c|c|c|c|}
\hline \multicolumn{10}{|l|}{$\begin{array}{l}\text { YAW DRIVE } \\
\text { SHAFT-PINION }\end{array}$} \\
\hline $\begin{array}{l}\text { SYSTEM } \\
\text { YAW GEARBOX }\end{array}$ & 1 & 1 & & & 1 & & 1 & & \\
\hline $\begin{array}{l}\text { SYSTEM } \\
\text { LUBRICATING }\end{array}$ & 1 & 1 & 1 & 1 & 1 & 1 & 1 & 1 & \\
\hline $\begin{array}{l}\text { SYSTEM } \\
\text { YAW MOTOR }\end{array}$ & & & 1 & & 1 & & & & 1 \\
\hline SYSTEM & 1 & 1 & 1 & 1 & 1 & 1 & 1 & 1 & \\
\hline $\begin{array}{l}\text { CLAMPING UNIT } \\
\text { SYSTEM } \\
\text { GEARBOX }\end{array}$ & 1 & 1 & 1 & 1 & 1 & 1 & 1 & 1 & \\
\hline $\begin{array}{l}\text { GEARBOX } \\
\text { COVER SYSTEM } \\
\text { GEARBOX }\end{array}$ & 1 & & 1 & & 1 & 1 & 1 & & \\
\hline $\begin{array}{l}\text { SUSPENSION } \\
\text { SYSTEM } \\
\text { PLANET } \\
\text { WHEELS }\end{array}$ & 1 & 1 & 1 & & & & 1 & 1 & \\
\hline $\begin{array}{l}\text { SYSTEM } \\
\text { SUN WHEEL }\end{array}$ & 1 & 1 & 1 & 1 & 1 & & & 1 & \\
\hline $\begin{array}{l}\text { SYSTEM } \\
\text { INTERNAL } \\
\text { GEARED RING }\end{array}$ & 1 & & 1 & & 1 & & & & \\
\hline $\begin{array}{l}\text { SYSTEM } \\
\text { TWO STAGE } \\
\text { FIXED AXIS } \\
\text { GEARED SYS- }\end{array}$ & 1 & & 1 & 1 & 1 & & 1 & & \\
\hline $\begin{array}{l}\text { TEM } \\
\text { LUBRICATING }\end{array}$ & & & 1 & 1 & 1 & & & 1 & \\
\hline $\begin{array}{l}\text { OIL SYSTEM } \\
\text { POWER FEEDER }\end{array}$ & 1 & 1 & 1 & 1 & 1 & & & 1 & \\
\hline $\begin{array}{l}\text { CABLES SYSTEM } \\
\text { GROUNDING }\end{array}$ & 1 & 1 & & & 1 & & & & 1 \\
\hline $\begin{array}{l}\text { SYSTEM } \\
\text { LIGHTNING } \\
\text { PROTECTION }\end{array}$ & 1 & 1 & & 1 & 1 & 1 & & & 1 \\
\hline $\begin{array}{l}\text { SYSTEM } \\
\text { ELECTRICAL } \\
\text { PROTECTION }\end{array}$ & & & & & 1 & & & & \\
\hline $\begin{array}{l}\text { SYSTEM } \\
\text { CAPACITOR }\end{array}$ & & & & & 1 & & & & 1 \\
\hline $\begin{array}{l}\text { BANK SYSTEM } \\
\text { THYRISTOR }\end{array}$ & 1 & 1 & & & 1 & & & 1 & 1 \\
\hline $\begin{array}{l}\text { SYSTEM } \\
\text { TRANSFORMER }\end{array}$ & 1 & & & & 1 & & & 1 & \\
\hline $\begin{array}{l}\text { SYSTEM } \\
\text { CONTROLLER }\end{array}$ & & & & & 1 & & & & 1 \\
\hline $\begin{array}{l}\text { SYSTEM } \\
\text { UNINTERRUPTI- } \\
\text { BLE POWER SUP- } \\
\text { PLY (UPS) SYS- }\end{array}$ & & & & & 1 & & & & 1 \\
\hline $\begin{array}{l}\text { TEM } \\
\text { SIGNAL } \\
\text { NETWORKING } \\
\text { HARDWARE }\end{array}$ & & & & & 1 & & & 1 & 1 \\
\hline $\begin{array}{l}\text { SYSTEM } \\
\text { METEOROLOGIC } \\
\text { AL STATION }\end{array}$ & 1 & 1 & & & 1 & & & & \\
\hline $\begin{array}{l}\text { SYSTEM } \\
\text { CABLE TWIST } \\
\text { PROTECTION }\end{array}$ & 1 & & & & & & & & \\
\hline $\begin{array}{l}\text { SYSTEM } \\
\text { HIGH SPEED } \\
\text { CENTRIFUGAL } \\
\text { RELEASE UNIT }\end{array}$ & 1 & 1 & 1 & & 1 & & & 1 & 1 \\
\hline SYSTEM & & & & & 1 & & & & 1 \\
\hline $\begin{array}{l}\text { ELECTRIC } \\
\text { MOTOR SYSTEM }\end{array}$ & & & & 1 & & & & & \\
\hline PUMP SYSTEM & & & 1 & & 1 & & & & 1 \\
\hline $\begin{array}{l}\text { OIL TANK } \\
\text { SYSTEM } \\
\text { FILTERS }\end{array}$ & 1 & & & & & 1 & & 1 & \\
\hline $\begin{array}{l}\text { SYSTEM } \\
\text { TUBING-HOSES }\end{array}$ & & 1 & & & 1 & 1 & & & \\
\hline $\begin{array}{l}\text { SYSTEM } \\
\text { (PIPE) FITTINGS } \\
\text { SYSTEM }\end{array}$ & 1 & 1 & 1 & 1 & 1 & 1 & & 1 & \\
\hline
\end{tabular}




\begin{tabular}{|c|c|c|c|c|c|}
\hline VALVES & & & & & \\
\hline $\begin{array}{l}\text { SYSTEM } \\
\text { ACCUMULATOR }\end{array}$ & & 1 & 1 & 1 & \\
\hline $\begin{array}{l}\text { SYSTEM } \\
\text { ACTUATORS }\end{array}$ & 1 & & 1 & 1 & 1 \\
\hline $\begin{array}{l}\text { SYSTEM } \\
\text { ROTATING }\end{array}$ & & & 1 & 1 & 1 \\
\hline $\begin{array}{l}\text { UNION SYSTEM } \\
\text { CENTRIFUGAL } \\
\text { RELEASE UNIT }\end{array}$ & & & 1 & & 1 \\
\hline SYSTEM & 1 & & 1 & 1 & \\
\hline
\end{tabular}

\subsection{2nd Parameter: Detectability}

The term Detectability refers to 1) the ease of detection of the failure according to the complexity of the structure of the system 2) the existence of a suitable detection method for the failure of the respective component. This parameter takes into consideration the number of detection methods that detect the failure and the Applicability parameter of these methods. The calculation of the Detectability parameter results in the final value for the Detection. Eq. 2, 3 .

$$
\begin{aligned}
& D_{h}=\sum_{m=1}^{m=9} A_{d} \\
& D=\left\{10-\left(\frac{D_{h}}{\max D_{h}} \times 10\right)\right\}+1
\end{aligned}
$$

Where $d$ is the detection methods that detect the failure (marked as red in Fig. 3). Eq. 2 calculates the sum of all the $D$ values of the methods that detect the failure. Eq. 3 considers the maximum value possible for the Detectability and is been subtracted by 10 to approach the 10-number-scale of Detection parameter. The additional value of 1 , is been added to avoid zero-sum values, which are not included in $D$ parameters evaluation. An example is given for the second failure in Fig, 3 (Yaw-drive shaft pinion system) which is detected by Vibration analysis, Ultrasonic, Thermography, and Shock Pulse method. These have $A_{d}$ values of 3, 2, 5, 1 respectively which add up in 11 . The $\max D_{h}$ value is 21 and from eq. 3 , the $D$ parameter is 6 . The aforementioned process results in $D$ values which will be substantially different from those evaluated with the traditional method (Tab. 3). For the previous example, the traditional method results in $D=2$ as it takes into consideration only the existence of detection methods for each failure to assign them low Detection values. Two-parameter evaluation does not approach each failure individually but estimates the ease of detection for each of them in the operation of the system. The RPN ranking with the proposed method is given in Tab. 7 .

\section{Results and Discussion}

The results of Tab. 7 suggest that the top-ranked failures belong to the Yaw system, Electrical and Control, and Gearbox. These results agree with the Final Publishable summary of ReliaWind Project (Nr 212966), which ranked the most critical subsystems, as shown in Fig 4. Subsystems that rank high are more prone to fail often and their failures affect the system on a multi-level basis. The detection of these failures is relatively difficult and the methods that detect them are not widely used in WTs. The results for average and standard deviation values are presented in Tab.6:
- Yaw system: The average value of $\mathrm{D}$, with the proposed method, is 5.4 and the standard deviation is 2.4. The other parameters $(\mathrm{S}, \mathrm{O})$ present lower average values $(2.4$ and 1.8 respectively) and standard deviation values of 0.5 and 1.7 which suggests that the components' failures are of the same magnitude. Therefore, the yaw system is ranked high overall, because the failures of its components are hard to detect in the early stages. These results, compile to difficulty in detecting the failures either because of the subsystem's complex structure or because of the lack of appropriate detection methods for the respective failures

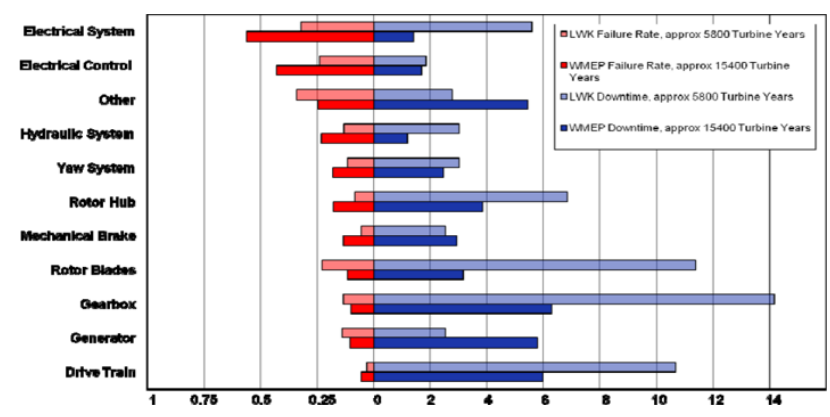

Fig. 3. Onshore WT failure rates and downtime results | Source: ReliaWind Project Nr 212966

- Gearbox system: The average value of D is 4.6 and the standard deviation is 1.7 in the case of the gearbox. Nevertheless, it is ranked as one of the most critical subsystems for the WT. The average values of $\mathrm{S}$ and $\mathrm{O}$ are 2.2 and 2.3 respectively and the standard deviation of 1.6 and 1.9 which suggests that the subsystem of the gearbox, for the case study, has low impact failures. There is a moderate to high evaluation of the detection difficulty of these failures indicating a need for real-time monitoring of the subsystem to avoid unexpected and undetected failures.

- Electrical system: This particular system has a D value average of 6.4 while the standard deviation value is 1.9 . The system is affected by failures that are difficult to detect, have minor effect on the operation of the system (S average 3.8) and do not occur regularly (O average 2.1).

- Control system: D average value, throughout the studied subsystems, is at the highest value, 7.3, while the standard deviation of the values is at 2.1. Control system is characterized, according to the results of the case study, by failures with low impact on the system's operation (S average 4.6) and low frequency of occurring (O average 2.3).

- Hydraulics system: D value for this subsystem is relatively high, at 6.2. Standard deviation (1.9) suggests that the failures occurring at the components are difficult to detect either because there is no detection method to detect some of them, or because the system is poorly designed. For $\mathrm{S}$ and $\mathrm{O}$ values, average and standard deviation are low $(2.7,1.4$ and $2.1,0.5$ ) which indicate that the failures are not severe and not frequent.

The information on the identification of the most critical subsystems and components, provide useful insights to maintenance operators and design teams [10]. Applying the knowledge acquired by this study, can reduce substantially the cost of maintenance. These results indicate that all the subsystems under study are affected by failures, which are not extremely severe for the operation of the system but are difficult to detect. The difficulty in detection lies at the complexity of the structure of the system and is affected by noise in the measurements due to the proximity of the rotating parts, with each other. In this study, the downtimes and the repair times of the individual failures have not been included. Some of 
them are occurring frequently and are difficult to repair or find replacements. The new approach, overall, estimates the $\mathrm{D}$ parameter with higher values than the average FMEA study. It should be noted that previous approaches of the parameter, tend to underestimate the values resulting in FMEA studies focused on mitigating the impact of the failure (S) or the frequency of the occurrence $(\mathrm{O})$.

Table 6. Average and Standard Deviation values for the S, O, D values for the 5 subsystems

\begin{tabular}{|c|c|c|c|c|c|c|}
\hline \multicolumn{2}{|c|}{ tor } & Yaw system & Gearbox & $\begin{array}{l}\text { Electrical sys- } \\
\text { tem }\end{array}$ & $\begin{array}{l}\begin{array}{l}\text { Control sys- } \\
\text { tem }\end{array} \\
\end{array}$ & $\begin{array}{l}\text { Hydraulic sys- } \\
\text { tem }\end{array}$ \\
\hline \multirow[t]{2}{*}{$\mathbf{S}$} & Average & 2.4 & 2.2 & 3.8 & 4.6 & 2.7 \\
\hline & Std. deviation & 0.5 & 1.6 & 1.9 & 0.8 & 2.1 \\
\hline \multirow[t]{2}{*}{$\mathbf{O}$} & Average & 1.8 & 2.3 & 2.1 & 2.3 & 1.4 \\
\hline & Std. deviation & 1.7 & 1.9 & 2 & 1 & 0.5 \\
\hline \multirow[t]{2}{*}{ D } & Average & 5.4 & 4.6 & 6.4 & 7.3 & 6.2 \\
\hline & Std. deviation & 2.4 & 1.7 & 1.9 & 2.1 & 1.9 \\
\hline
\end{tabular}

Table 7. RPN calculations for the failures of the components under study

\begin{tabular}{|c|c|c|c|c|c|}
\hline Subsystem & Component & $\mathbf{S}$ & $\mathbf{O}$ & $\mathbf{D}$ & RPN \\
\hline \multirow{5}{*}{ 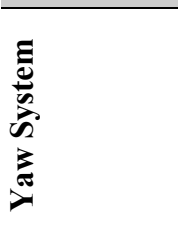 } & Failure of Internal Gear Slewing Bearing System & 2 & 5 & 8 & 80 \\
\hline & Failure of Yaw Drive Shaft-Pinion System & 3 & 1 & 4 & 12 \\
\hline & Failure of Yaw Gearbox System & 2 & 1 & 8 & 16 \\
\hline & Failure of Lubrication System & 3 & 1 & 4 & 12 \\
\hline & Failure of Yaw Motor System & 2 & 1 & 3 & 6 \\
\hline \multirow{8}{*}{ 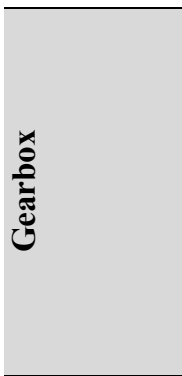 } & Failure of Clamping Unit System & 2 & 1 & 6 & 12 \\
\hline & Failure of Gearbox Cover System & 1 & 1 & 3 & 3 \\
\hline & Failure of Gearbox Suspension System & 2 & 1 & 5 & 10 \\
\hline & Failure of Planet Wheels System & 1 & 2 & 6 & 12 \\
\hline & Failure of Sun Wheel System & 5 & 2 & 6 & 60 \\
\hline & Failure of Internal Gear Ring System & 2 & 2 & 1 & 4 \\
\hline & Failure of Two Stage Fixed Axis Geared System & 4 & 2 & 5 & 40 \\
\hline & Failure of Lubrication Oil System & 5 & 7 & 5 & 175 \\
\hline \multirow{15}{*}{ 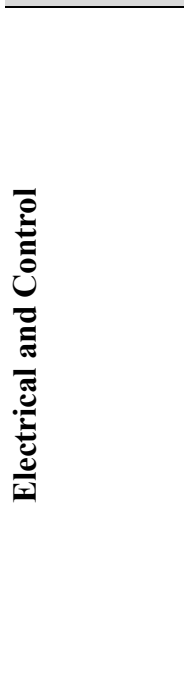 } & Electrical System & & & & \\
\hline & Failure of Power Feeder Cables System & 4 & 1 & 4 & 16 \\
\hline & Failure of Grounding System & 5 & 1 & 8 & 40 \\
\hline & Failure of Lightning Protection System & 5 & 1 & 6 & 30 \\
\hline & Failure of Electrical Protection System & 5 & 4 & 8 & 160 \\
\hline & Failure of Capacitor Bank System & 5 & 6 & 9 & 270 \\
\hline & Failure of Thyristor System & 2 & 1 & 6 & 12 \\
\hline & Failure of Transformer System & 0 & 1 & 4 & 4 \\
\hline & Control System & & & & \\
\hline & Failure of Controller System & 5 & 2 & 8 & 80 \\
\hline & Failure of Uninterruptible Power Supply (UPS) & 5 & 3 & 8 & 120 \\
\hline & Failure of Signal Networking Hardware System & 5 & 4 & 6 & 120 \\
\hline & Failure of Meteorological Station & 3 & 2 & 10 & 60 \\
\hline & Failure of Cable Twist Protection System & 5 & 2 & 8 & 80 \\
\hline & Failure of High-Speed Centrifugal Release Unit & 5 & 1 & 4 & 20 \\
\hline \multirow{9}{*}{ 总 } & Failure of Electric Motor System & 1 & 1 & 7 & 7 \\
\hline & Failure of Pump System & 5 & 1 & 7 & 35 \\
\hline & Failure of Oil Tank System & 1 & 1 & 7 & 7 \\
\hline & Failure of Filters System & 1 & 2 & 9 & 18 \\
\hline & Failure of Tubing-Hoses System & 1 & 2 & 5 & 10 \\
\hline & Failure of (Pipe) Fittings System & 1 & 2 & 6 & 12 \\
\hline & Failure of Valves System & 5 & 1 & 7 & 35 \\
\hline & Failure of Rotating Union System & 5 & 2 & 2 & 20 \\
\hline & Failure of Centrifugal Release Unit & 5 & 1 & 6 & 30 \\
\hline
\end{tabular}




\section{Conclusions}

In this paper, a novel approach to evaluating Detection in FMEA studies was proposed. The main task was to propose an evaluation method that can be applied to every system and which considers the complex mechanisms linking the respective components. In order to show the application of the twoparameter approach, which introduces the parameters of Applicability of the Detection method to the complexity of the system and the Detectability of the failure, a case study was presented. The proposed method takes into consideration only the most critical subsystems, resulting to the detection of the components with the higher RPNs. The results of the study highlighted the importance of the Detection parameter, as there was no mathematical way to determine it, in the best knowledge of the authors. The novelty of the method was supported by similar studies (as ReliaWind Project), which confirmed the prioritization of the criticality of the subsystems under study. Lack of historical data, leads to some modifications for the evaluation of the parameters of FMEA. In conclusion, the two-parameter approximation presented promising results that will drive the next steps of this research.

This is an Open Access article distributed under the terms of the Creative Commons Attribution License

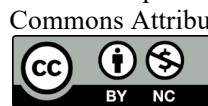

\section{References}

1. GWEC. Global wind energy council report 2018 2019;(April):1-61.

2. Performance E, Directive B. Energy Efficiency and Renewable Energy Handbook, vol. 2013; 2020.

3. 2018 Wind Technologies Market Report 2018;(June):1-98.

4. IRENA International Renewable Energy Agency. Renewable Power Generation Costs in 2017; 2018.

5. EIA. Levelized Cost and Levelized Avoided Cost of New Generation Resources. Annual Energy Outlook 2019 2019;(February 2019).

6. Sharpe D, Sharpe D. Wind energy handbook. John Wiley \& Sons, Ltd; 2001.

7. Bechtle P, Schelbergen M, Schmehl R, Zillmann U, Watson S. Airborne wind energy resource analysis. Renewable energy 2019;141:1103-1116.

8. Mil-Std U. 1629.“. Failure Mode and Effects Analysis” Available from the National Technical Information Service, Spring- held, Virginia 1980;.

9. Bennouk A, Nejmi A. Wind turbine failures analysis based on performances study and FMECA. Proceedings of the 2018 International Conference on Optimization and Applications, ICOA 2018 2018;p. $1-6$.

10. Zhou A, Yu D, Zhang W. A research on intelligent fault diagnosis of wind turbines based on ontology and FMECA. Advanced Engineering Informatics 2015;29(1):115-125.

11. Guerrero AC, Guillen AJ, Gomez JF. A process to develop a quantitative FMECA analysis of critical systems in an offshore wind turbine. Proceedings of 2013 International Conference on Renewable Energy Research and Applications, ICRERA 2013 2013;(October):590-594.
12. Gilchrist W. Modelling failure modes and effects analysis. International Journal of Quality \& Reliability Management 1993;.

13. N R Sankar BSP. Modihed approach for prioritization of failures in a system failure mode and effects analysis. Interna- tional Journal of Quality and Reliability Management 2001;18(3):324-335.

14. Chang KH, Chang YC, Lai PT. Applying the concept of exponential approach to enhance the assessment capability of FMEA. Journal of Intelligent Manufacturing 2014;25(6):1413-1427.

15. Akbarzade Khorshidi H, Gunawan I, Ibrahim MY. Applying UGF Concept to Enhance the Assessment Capability of FMEA. Quality and Reliability Engineering International 2016;32(3):1085-1093.

16. Bowles JB, Peláez CE. Fuzzy logic prioritization of failures in a system failure mode, effects and criticality analysis, Reliability Engineering and System Safety 1995;50(2):203-213.

17. NAVAIR. Reliability Centered Maintenance, RCM. Second ion 2008;

18. Ostachowicz W, McGugan M, Schröder-Hinrichs JU, Luczak M. MARE-WINT: new materials and reliability in offshore wind turbine technology. Springer; 2016.

19. Konstantinidis E, Botsaris P. Wind turbines: current status, obstacles, trends and technologies. In: IOP Conference Series: Materials Science and Engineering, vol. 161 IOP Publishing; 2016. p. 012079.

20. Konstantinidis EI, Katsavounis S, Botsaris PN. Design structure matrix (DSM) method application to issue of modeling and analyzing the fault tree of a wind energy asset. Wind Energy 2019;(March):118.

21. Ford Motor Company. Failure Mode and Effects Analysis, FMEA Handbook .International Journal of Quality \& Reliability Management 2011;13(5):286. 